This is the author accepted version. Readers should cite the published version.

Knight, S. (2020). Augmenting Assessment with Learning Analytics. In M. Bearman, P. Dawson, R. Ajjawi, J. Tai, \& D. Boud (Eds.), Re-imagining University Assessment in a Digital World. Springer.

https://doi.org/10.1007/978-3-030-41956-1 10 


\section{Augmenting assessment with learning analytics}

ABSTRACT: Learning analytics as currently deployed has tended to consist of large-scale analyses of available learning process data to provide descriptive or predictive insight into behaviours. What is sometimes missing in this analysis is a connection to human-interpretable, actionable, diagnostic information. To gain traction, learning analytics researchers should work within existing good practice particularly in assessment, where high quality assessments are designed to provide both student and educator with diagnostic or formative feedback. Such a model keeps the human in the analytics design and implementation loop, by supporting student, peer, tutor, and instructor sense-making of assessment data, while adding value from computational analyses.

\section{Introduction to Learning Analytics}

Rising use of digital technology across education has heralded an increased focus on the potential of data to inform our understanding of student learning. Increasing attention to learning data has come from a number of sub-disciplines in education, most recently the emergence of 'Learning Analytics', a field with specific focus on the use of data derived from student learning to inform that learning. As Ferguson's (2012) “The State of Learning Analytics in 2012: A Review and Future Challenges" charts, the developmental trajectory of learning analytics has been driven by an interest in applying business intelligence techniques to the increasing amounts of data made available through virtual learning environments and other learning systems. This interest has shifted from primary concerns around accountability and efficiencies, to an increasing focus on pedagogic concerns.

The field of learning analytics has seen keen interest in understanding how to effectively implement novel techniques, which support learning. Across educational stakeholders there is an increasing desire to use data effectively to inform and understand practice; in particular, there is a strong desire to achieve impact through implementing and supporting effective learning strategies. Learning analytics can contribute to this, but to do so, we need to develop a deeper understanding of the kinds of problems it can tackle, and how to integrate analytics into practical pedagogic contexts.

There is a growing expectation that educators use data as a form of evidence of student learning (and course evaluation). This shift in focus onto learning analytics as a form of assessment data highlights two intertwined concerns. First, as others have noted, educators must have a degree of data literacy to be able to navigate the, often quantitative, information that they are provided with (see, for examples, Mandinach, 2012; Mandinach \& Gummer, 2016). Second, this data literacy must have a focus on how data is used in context to make decisions. Such a perspective prompts a move beyond simply supporting educators in navigating large-scale assessment data or predictive models based on Learning Management System (LMS) log data, to supporting educators in making practical decisions about the data they collect and make decisions on.

This chapter focuses in on a particular component of those challenges, suggesting that a key path for the impact of learning analytics is a focus on 'intelligence augmentation' (IA) over artificial 
intelligence $(\mathrm{AI})^{1}$. That is, rather than focusing on how artificial intelligence might be deployed for automation of tasks, I shift focus to explore how artificial intelligence can augment assessment, in particular by amplifying the impact of high quality assessment with learning analytics derived feedback. Such an approach has dual benefits, in 'bringing along' educators in the implementation of learning analytics, though supporting their existing practice rather than requiring wholescale changes, and provides sites for learning analytics in which there is clear pedagogic potential through understanding that existing practice.

In this chapter, I introduce a broad model of assessment as a fundamental design context for educators. I then present three ways in which learning analytics might intersect with this model, arguing that 'augmenting assessment with learning analytics' provides for particular benefits. I will then illustrate this approach using a particular assessment context (peer assessment), and various sites for augmentation in that context, drawing on examples from the literature to do so.

\section{Understanding Assessment as Design}

In this chapter I frame assessment building on the social constructivist model of assessment processes in Rust, O’Donovan and Price (2005). I take it that when educators set about designing assessments, their fundamental question is "How do we get knowledge of what the students know?" (Committee on the Foundations of Assessment, 2001). A key part of this assessment process is the bringing to alignment of student and educator expectations around what is to be learnt, with active engagement with criteria development and feedback from both educators and students (Rust et al., 2005).

In a simplified model based on this perspective (Figure 1), educators across educational levels engage in assessment design as a component of their course design. In so doing, they design assessment tasks and criteria by which to assess the completion of those tasks (the top box in Figure 1). In order to undertake this design work, educators should have a rich understanding of the learning context alongside the assessment literacy to design and deploy tasks to probe learning. They must, therefore, understand how the assessment is related to the students learning, how assessments are constructed (by themselves or others) as measurement tools (e.g. validity, feedback, etc.), and knowledge of the range of assessment types and responses to them (Price, Rust, O'Donovan, Handley, \& Bryant, 2012). At most basic, educators might consider whether the assessment is summative in nature (sometimes called 'assessment of learning') - end of unit examinations, for example - or is intended to provide formative feedback towards further learning (sometimes called 'assessment for learning').

Influencing this process are characteristics such as the educator's epistemic cognition (how they think about the student's knowledge and the influence of that on their instruction) (Barnes, Fives, \& Dacey, 2017; Fives, Barnes, Buehl, Mascadri, \& Ziegler, 2017). That is, when educators create assessments they are making judgements about what they would like their students to attain, and must consider the question "what will I learn about my students from the formative assessment event?" (Fives et al., 2017, p.3). Even in a simplified model such as the one below, we hope that educators will also engage in a reflective process of using the students' outcomes in

\footnotetext{
${ }^{1}$ For an introduction to this idea, see https://theconversation.com/artificial-intelligence-holds-great-potential-forboth-students-and-teachers-but-only-if-used-wisely-81024
} 
their assessments to (a) drive instruction, and (b) revise the assessment tasks for future iterations. That is, that the assignments students submit are a learning opportunity to develop courses and modules, as well as to develop the students' individual learning.

As a part of this process of assessment - as reflected in the lower box in Figure 1 - students of course must complete the assessment tasks, and receive marks on them against the criteria. Again, here, in addition to the content knowledge, students must engage a degree of assessment literacy, to understand what is being asked of them and how best to display this (Price et al., 2012). On receipt of their feedback (perhaps in written form alongside grades or rubrics), they should also engage in a reflective/metacognitive cycle, again influenced by individual differences such as achievement goals, and epistemic cognition (Muis \& Franco, 2009; O’Donovan, 2017).

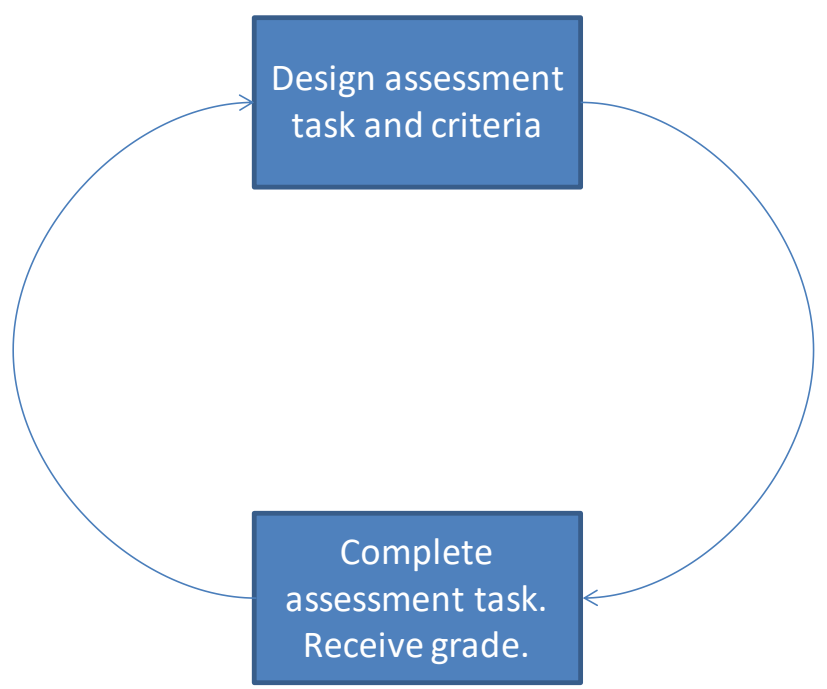

Figure 1 - A Simplified Assessment Model, in which educators design assessments that students complete

To extend this simplified model, increased attention has been paid to the implementation of feedback and feedforward cycles in assessment processes. Feedforward is formative feedback that supports students in understanding the assessments they will complete and their criteria, through engagement with criteria (perhaps even writing their own) and exemplars, and so on (Wimshurst \& Manning, 2013). Feedback, then, is formative feedback provided post-assessment activity to support students in understanding why they received the mark that they did, and how they might improve in the future. Thus, Figure 2 indicates a cycle of assessment with feedback and feedforward; breaking down possible sites for augmentation with learning analytics. 


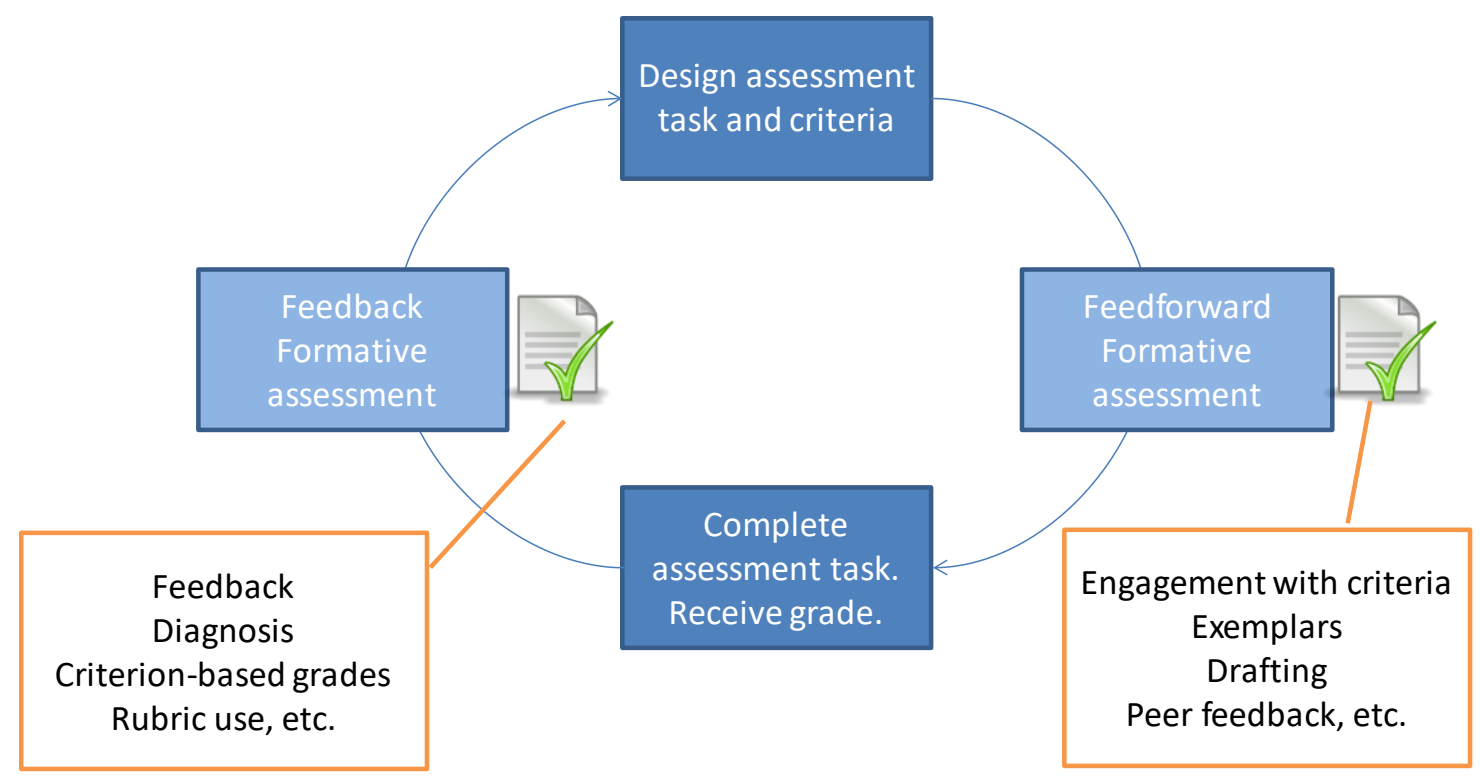

Figure 2 - Assessment with Feedforward and Feedback

\section{Models for Transforming Assessment with Learning Analytics}

One way of conceiving of learning analytics and its role in teaching and learning is as a tool for assessment (Knight, Buckingham Shum, \& Littleton, 2014). In this model, through the analysis of process-based trace data and artefacts created in learning tasks, researchers and other stakeholders aim to make claims about that learning, at any one of the four components above. For example, we might provide feedback on a written essay (artefact), or the writing process (process), and this feedback might come before or after the final submission, provided to the student, or to support the educator in evaluating and revising their assessment design. In this understanding of learning analytics, we can further conceive of two broad approaches.

One potential is for learning analytics to facilitate a shift away from the summative assessment of artefacts produced. Instead, learning analytics might facilitate more process-based assessments such as choice based assessments, that explore the meaningful choices that students make in completing tasks (Schwartz \& Arena, 2013), and the processes undertaken in 'performance assessments' of authentic tasks (Benjamin et al., 2009; Darling-Hammond \& Adamson, 2010; Linn, Baker, \& Dunbar, 1991; Pellegrino, 2013; Stecher, 2010). New forms of feedback can thus make use of the trace data in "data-rich" learning (Pardo, 2017). However, work adopting this approach requires the collection of new types of data, potentially using new technologies to collect that data, to be represented back to learners and educators in ways that also require research. The development of assessments based on novel process-based data is challenging, as work on intelligent tutoring systems has shown.

Thus, this development is likely to be time-consuming, expensive, and require systemic changes. As Roll and Wylie (2016) note in the context of the $25^{\text {th }}$ anniversary of the Journal of Artificial Intelligence in Education, in order to achieve impact in education, researchers should undertake two strands of research: evolutionary, with a focus on existing classroom practice; and revolutionary, with a focus on more wholescale change of systems. This former, evolutionary 
approach, then, looks at how learning analytics can augment existing systems. In contrast the latter might involve development of new types of assessment, and the automation of existing assessments to create structural change in systems. These three approaches will be discussed, followed by a focus on the potential of augmenting in the rest of this chapter.

\section{Approach 1: Learning Analytics for New Types of Assessment}

Learning analytics for new types of assessment: First, learning analytics can be developed to assess constructs that were not readily assessable using traditional methods. This including approaches such as intelligent tutoring systems, or choice based and performance assessments, that follow procedures such as evidence centred design (Mislevy, Behrens, Dicerbo, \& Levy, 2012) which provide a logic for mapping behaviours to target constructs (such as self-regulation, collaboration, etc.). In this model, whole assessment structures can be redesigned, with criteria based on fine-grain analysis of the knowledge components in a domain, and feedback and task completion based around completing defined activities with practice algorithmically oriented to the target constructs.

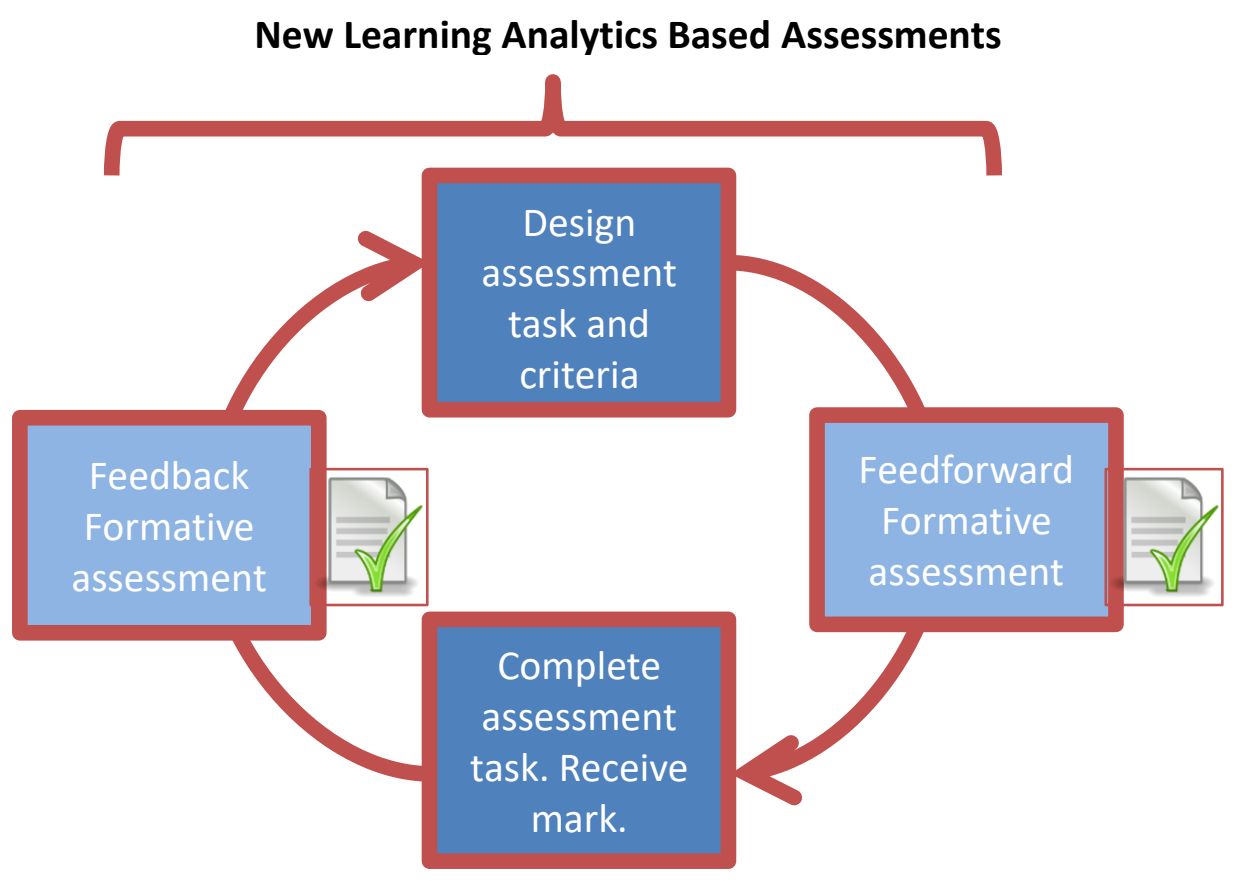


Approach 2: Learning Analytics to Automate Assessments

Learning analytics to automate assessment: Second, learning analytics can be used to automatize existing assessment structures. Thus, rather than tutors or instructors engaging in grading, a system is developed to automatically assess, for example through the automated essay scoring systems (Shermis \& Burstein, 2013). In this model, substantial portions of the assessment structure may remain static, with analytics targeted either at the automation of existing work (e.g., automated essay scoring), or at scoring based on process data collected in the creation of artefacts aligned with existing assessments.

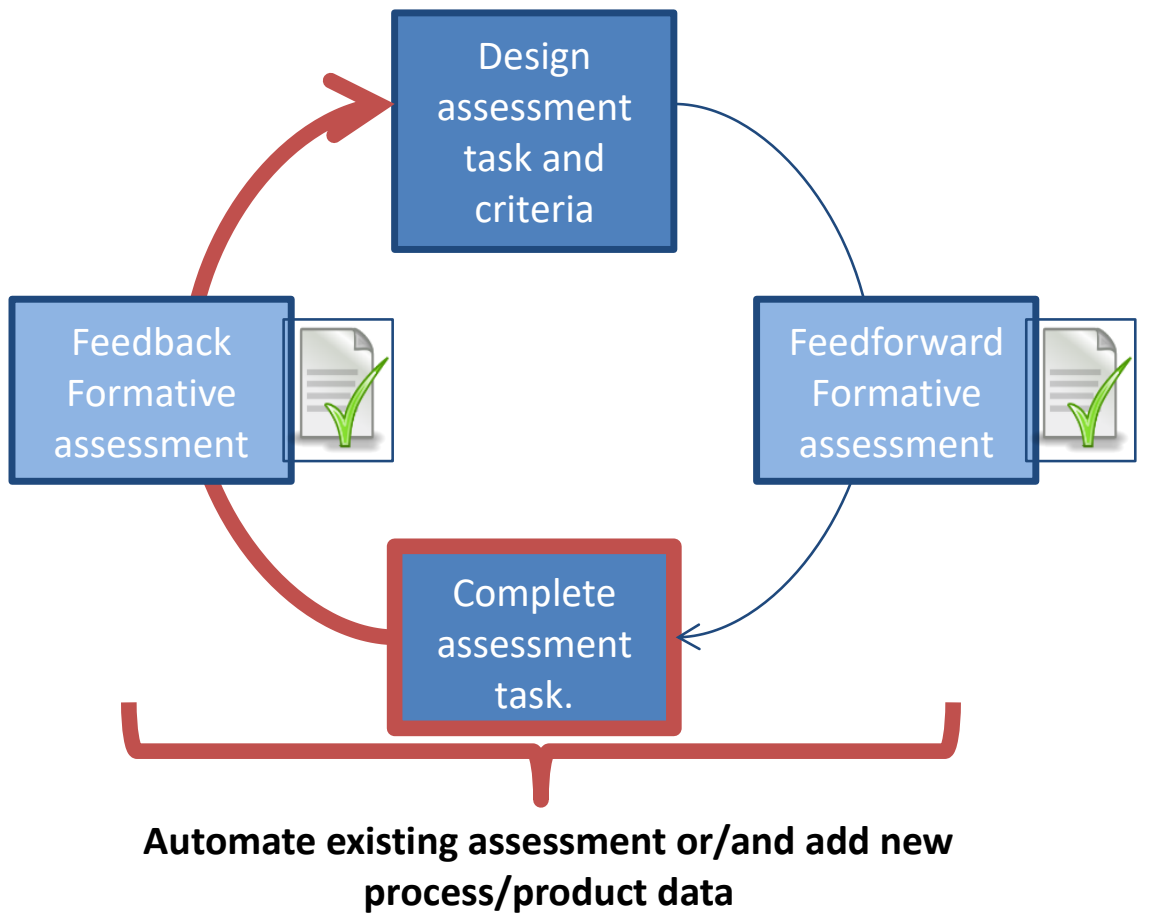

Approach 3: Learning Analytics to Augment Assessment

Learning analytics to augment assessment: Lastly - and the focus of this chapter - learning analytics can be used to augment assessment, to support the analysis and feedback on existing produced artefacts or process in the context of well-established effective e-assessment or technology enhanced assessment. That is, rather than focusing on developing new assessments or methods of completing assessment, instead focus on augmenting existing assessment structures through the augmentation of feedback and feedforward processes for effective assessment. In this model, rather than seeking to automate grading (or enrich it through analysis of process data), the focus is on the formative feedback and the potential of learning analytics in that space. As highlighted below, this approach has some distinctive benefits. 


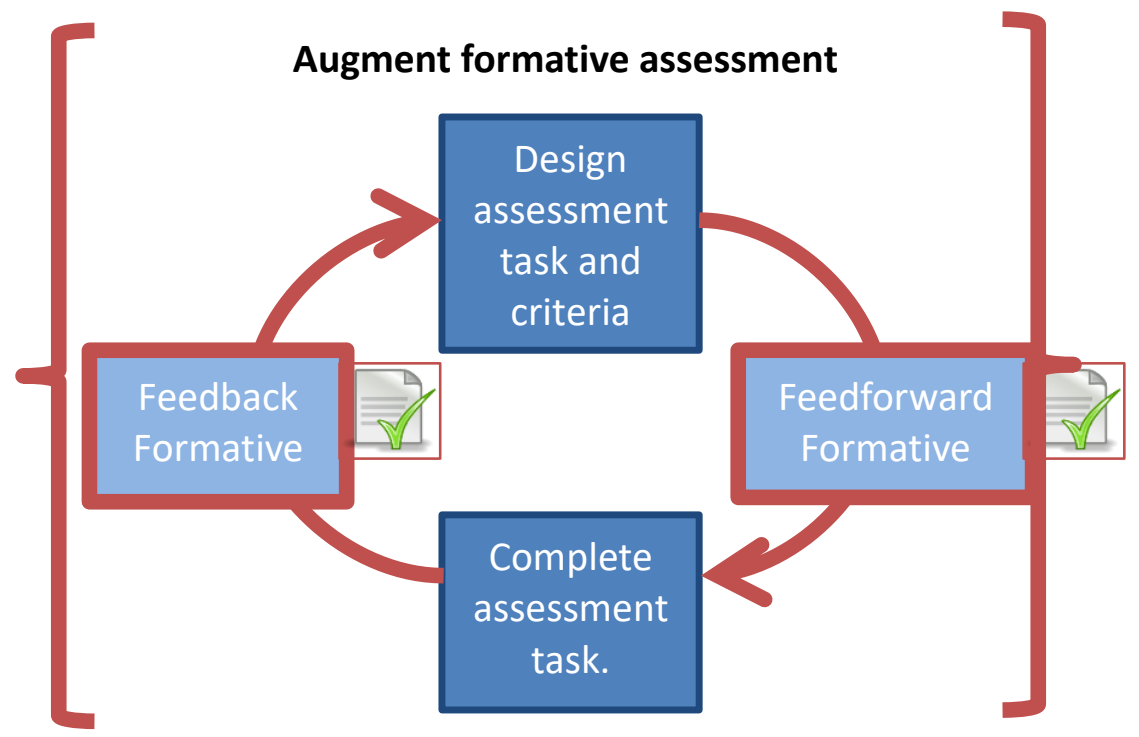

This chapter argues that to achieve maximum impact and adoption, educators and learning analytics researchers should work together to develop approaches to assessment augmented by learning analytics. Such augmentation has a dual effect of increasing adoption of learning analytic approaches, thus potentially opening the door to more revolutionary (than evolutionary) changes, while also increasing adoption of existing good practice through the support of that practice via learning analytics.

\section{Benefits of Augmenting Assessment with Learning Analytics}

Writing in the 25th anniversary issue of the International Journal of Artificial Intelligence in Education (IJAIED), Baker (2016) suggests that AI researchers working in the education space should shift focus. In that piece, Baker notes that adoption of AI technologies in education has not been widespread. He thus suggests that, instead of developing ever smarter intelligent tutoring systems, researchers might instead focus on amplifying human intelligence, supporting humans to make decisions through the use of intelligently designed systems. Such a proposal would, for example, shift attention away from auto-scoring systems, and towards using the same data to report to educators and students in intelligently, to support them in making decisions.

Baker notes a number of potential advantages to such an approach, including that it provides for more flexibility of response and intervention. This is because such an approach does not necessitate the assumption that students in the future will have the same behaviours as those modelled now, nor that the interventions remain the same. That is, a risk of automating existing processes is that it reifies existing practice in both assessment and outcome, where this may not be appropriate. An augmented approach, then, does not - necessarily - require the large scale design and implementation of pedagogic agents, which is an expensive and time consuming process. Instead, the focus is on how technologies can be used flexibly to augment intelligence.

As Zhao, Pugh, Sheldon and Byers (2002) highlight, the distance of any innovation from existing: culture, practice, and technological resources, will impact its uptake by educators. That is, innovations will not be taken up that: are counter to existing cultural context; do not align well with practices of individual educators; or require significant change to available technology. In a similar vein, in their introduction to a panel discussion on overcoming barriers to achieve adoption of learning analytics, Ferguson et al., (2014) note the need to consider: 
- institutional context and culture;

- buy-in from stakeholders; and

- understanding of specificity and user needs.

Distinct advantages of focusing on the potential of learning analytics to augment assessment are that such an approach should: align better with existing culture and practice; be less likely to require significant technological change; and keep decision making firmly within the autonomy of the educator. As such, this approach is a way to support and enhance existing practice, raising awareness of the potential of learning analytics, in turn increasing the potential for impact from those analytics in existing and novel applications. Although over a longer term a focus on systems change - and implementation of new assessment structures - is likely to be an important component of educational improvement, I suggest that this is more likely - not less - with a key focus on augmentation of assessment with learning analytics. As such three key advantages of augmentation emerge:

1. Augmentation provides for easier integration

2. Augmentation is more flexible in use

3. Augmentation has lower upfront cost

In proposing this approach, an explicitly design oriented perspective is taken. As Lockyer, Heathcote, and Dawson (2013) highlight, because learning analytics provides new methods for data capture (in place of self-report methods), it can help educators in testing their assumptions regarding their learning design. Learning analytics, then, offers the potential to deliver on the promise of technology enabled assessment for learning (Crisp, Guàrdia, \& Hillier, 2016; Dawson $\&$ Henderson, 2017), with feedback to students identified as one key target for such analytics (Timmis, Broadfoot, Sutherland, \& Oldfield, 2016). By augmenting assessments with learning analytics, educators and students can receive a richer picture of what learning is taking place, and be supported in both developing the learning tasks and their responses towards those tasks.

\section{Augmenting Assessment with Learning Analytics: A Worked Example}

In this model, then, developing approaches in learning analytics would be used to provide feedback to students and educators for their educational decision making. This feedback might be diagnostic or formative in nature, providing information on specific areas of weakness and providing information on how particular features of their learning might be changed. Such augmentation might also simply provide additional information to stakeholders that they could use to support their decision making. For example, topic modelling might indicate that students wrote about two themes - a piece of non-normative or evaluative information - which could be used to target specific feedback content.

In the following sections some key advantages of this approach are drawn out through their exemplification in a particular set of design cases. These designs are based on a basic model of peer assessment, which may be used in both feedback and feedforward contexts. Each of these designs has in fact been implemented as indicated by citations throughout, although the combined set of design patterns has - to the best of my knowledge - not been brought together. In highlighting these designs, I wish to draw attention not only to the specific uses being 
developed, but also to the general approach to augmentation and its potential to improve the adoption and integration of data informed approaches in education.

\section{Peer assessment}

In peer assessment models, students engage in assessing their peers' works for formative or summative purposes, while their own work is assessed by those same peers. The benefits of peer assessment for learning are well documented (for example, Topping, 1998), with increased attention on specific design configurations to support its effective implementation (Strijbos \& Sluijsmans, 2010). In addition, peer assessment can produce reliable grade-feedback (for example, K. Cho, Schunn, \& Wilson, 2006), and has clear potential in e-learning contexts (D. Whitelock, 2010).

However, amongst both students and educators, there is often a focus on the potential of peer assessments to reduce the staff marking burden, and other features that relate to structural concerns around the fairness, efficacy, and quality of peer assessment. Students can have a perception that peer assessment is inaccurate or unreliable, thus reducing their motivation to participate, in addition to which students (like other assessors) do in fact disagree. To address these concerns, multiple designs can be adopted that augment a basic peer assessment design such as that shown in Design 1 below. These designs may be further augmented by learning analytics, as indicated in the following iterations.

\section{DESIGN 1: Peer Assessment}

Problem: We want our students to develop their assessment literacy through applying the assessment criteria, and providing and receiving feedback on their work for formative purposes.

Task: Peer assessment involves students assessing each other's work, typically prior to submitting a final version of the same work.

Tools/materials and participant structures: Peer assessment is typically conducted individually, often with students asked to assess multiple assignments (although this requirement may be removed for formative purpose). Assessment is typically anonymous, and involves provision of both a score and comment.

Iterations and Augmentation: Peer assessment may be used as a stand-alone assessment design, or augmented by one of the designs below. 
Developing the basic peer assessment design, we can add a number of complementary designs, that extend peer assessment, and may be augmented by learning analytics. For example, in design 2, we see the addition of automated peer-allocation. This simple technique - based on prior assessment data, automated essay scoring, or topic modelling - can be used to allocate peers in a way to support all students learning. For example, prior research indicates that all students can benefit from feedback from lower achieving students, but that low ability students tend to benefit more from students who are similar to them (K. Cho, Schunn, \& Charney, 2006). So, it may be desirable in a number of contexts to assign peer assessment artefacts on the basis of prior knowledge, the content of the artefact, or some other features.

\section{DESIGN 2: Peer Allocation}

Problem: Peers may be assigned texts that are not aligned with their content knowledge, or that fail to support their learning (because they are misaligned in terms of quality).

Task: This design complements the peer assessment design (design 1). In peer assessment, students can be assigned to assess either convergent or divergent work (i.e. work that is of a similar quality/topic as their own, or diverges from their own).

Tools/materials and participant structures: As in peer assessment.

Iterations and Augmentation: Learning analytics can be used to allocate peers automatically based on content or ability, for example, using prior assessment data, automated essay scoring, or topic modelling.

In addition, design 3 provides a complementary pattern that introduces a 'calibration' or benchmarking task, in which students engage with assessing exemplar texts prior to their own task completion. Such tasks have, as with peer assessment more generally, often been discussed in the context of training for peer-assessment as a means to reduce the marking burden (for example, in calibrated peer review, see e.g. Balfour, 2013). However, calibration tasks have a

\section{DESIGN 3: Calibration Tasks}

Problem: Students should (1) critically apply the assessment criteria to artefacts of the form they will produce, (2) engage actively with exemplars, (3) calibrate their judgement of their own and other's work based on feedback (directly, and mediated via the diagnostic information provided to an instructor)

Task: Students are asked to assess exemplars, typically 3-5 artefacts of varying quality or on different topics. Students use the assessment criteria to assess these exemplars, providing a grade or point score, alongside written feedback. Once they have done this, students can be provided with feedback on the 'accuracy' of their assessments, as well as seeing both instructor and peer feedback provided to the same exemplars. This design complements design 1 , and can be used as a standalone task.

Tools/materials and participant structures: This task is typically conducted in individual, then group, structures, with students assessing individually (perhaps after a period of discussion of the criteria), and then discussing the collective feedback.

Iterations and Augmentation: Diagnostic feedback can be provided to students and instructors in a number of ways. First, student judgements provide insight into how aligned they (individually, and as a cohort) are with the instructor's assessments of the same artefacts. Second, students can be provided with support in giving high quality feedback, through the use of natural language processing on their written comments. This feedback has been shown to produce higher quality comments from students, which we would anticipate supporting their learning about the criteria and thus developing their own evaluative judgement. 
richer potential in engaging students in the application of assessment criteria to known exemplars, and the ensuing potential for diagnostic feedback and discussion about their judgements. In peer assessment, it is often the giving (not receiving) of feedback that students learn most from (K. Cho \& MacArthur, 2011; Y. H. Cho \& Cho, 2011; Lundstrom \& Baker, 2009; Nicol, Thomson, \& Breslin, 2014). Similarly, in calibration tasks we would expect that by engaging students in giving feedback, they will learn. As such, supporting students in calibrating their judgement and feedback should support their assessment of their own work and address the concern that student's feedback can be misaligned with that of their tutors (McConlogue, 2015; Patchan, Charney, \& Schunn, 2009; Rollinson, 2005; Watson \& Ishiyama, 2012). One potential means through which to provide this support is in the form of 'feedback on feedback'; that is, automated feedback on the quality of feedback that has been provided (typically in written form). This feedback might, for example, simply analyse student comments for phrases and words that are related to feedback categories (D. Whitelock et al., 2012; D. Whitelock, Pinto, \& Saez, 2010), or investigate the kinds of feedback that are in fact acted on, and relate these to textual features of the feedback (Nelson \& Schunn, 2009; Nguyen, Xiong, \& Litman, 2017; Yadav \& Gehringer, 2016).

Finally, peer assessment may also be augmented through providing students with targeting towards specific features of the artefacts they are asked to assess. This differs from design 3 , in that design 3 is focused on specific features of the feedback, while design 4 also draws on specific features of the assessed artefact. As such, design 4 provides a mechanism to focus feedback. In some regards this design is similar to a complementary design (not expanded here) in which students are scaffolded in completing their peer assessment through the use of rubrics or specific questions (see, for example, Gielen \& De Wever, 2015), and indeed, such structuring may also be useful. Learning analytics can augment this approach by specifically foregrounding target features in the artefacts to the assessors, who then choose to use this support in writing their feedback. That is, the peer feedback can be used to mediate automated feedback via the peer's elaboration and focusing. For example, in the Academic Writing Anlytics (AWA) project (see, for example, Knight, Buckingham Shum, Ryan, Sándor, \& Wang, 2017), natural language processing is conducted on student writing to detect the presence of 'rhetorical moves' (rhetorical structures in the text that provide structural markers to the reader). In preliminary work, peers have been asked to provide feedback to each other on their work, making use of the AWA tool to particularly foreground rhetorical structures in their comments (see, for example, Shibani, 2017, 2018; Shibani, Knight, Buckingham Shum, \& Ryan, 2017).

\section{Conclusion}

Learning analytics can be used to support assessment processes, in the provision of feedback to both learners and educators regarding evidence of learning. This paper has discussed different ways in which learning analytics can be integrated into practical pedagogic contexts. This chapter has argued that one means through which learning analytics can achieve impact is through augmenting assessment design. Impact will be achieved by combining learning analytics with effective assessment through the kind of augmentation approach described here. I have argued that technology integration is a key consideration in taking this approach as a means to 
achieve impact with learning analytics. The flexibility of use of learning analytics in the context of designing assessments has been illustrated at a basic level through a set of peer assessment design patterns which illustrate how learning analytics can augment assessment. In each case, a core assessment design is highlighted, with the potential to augment that design with learning analytics tools demonstrated. By adopting such an approach, we can foster the testing and development of learning analytics with educators in the loop, making key decisions about how analytics relate to and impact their teaching contexts, and provide support for existing good practices in assessment design.

\section{References}

Baker, R. S. (2016). Stupid tutoring systems, intelligent humans. International Journal of Artificial Intelligence in Education, 26(2), 600-614. Retrieved from http://link.springer.com/article/10.1007/s40593-016-0105-0

Balfour, S. P. (2013). Assessing writing in MOOCs: Automated essay scoring and calibrated peer review. Research \& Practice in Assessment, 8(1), 40-48. Retrieved from http://www.rpajournal.com/dev/wp-content/uploads/2013/05/SF4.pdf

Barnes, N., Fives, H., \& Dacey, C. M. (2017). U.S. teachers' conceptions of the purposes of assessment. Teaching and Teacher Education, 65, 107-116. https://doi.org/10.1016/j.tate.2017.02.017

Benjamin, R., Chun, M., Hardison, C., Hong, E., Jackson, C., Kugelmass, H., ... Shavelson, R. (2009). Collegiate Learning Assessment. Retrieved from http://www.plu.edu/assessment/widgets/documentsforms/items/Returning\%20to\%20Learning\%20Document.pdf

Cho, K., \& MacArthur, C. (2011). Learning by reviewing. Journal of Educational Psychology, 103(1), 73. Retrieved from http://psycnet.apa.org/journals/edu/103/1/73/

Cho, K., Schunn, C. D., \& Charney, D. (2006). Commenting on writing typology and perceived helpfulness of comments from novice peer reviewers and subject matter experts. Written Communication, 23(3), 260-294. Retrieved from http://wcx.sagepub.com/content/23/3/260.short 
Cho, K., Schunn, C. D., \& Wilson, R. W. (2006). Validity and reliability of scaffolded peer assessment of writing from instructor and student perspectives. Journal of Educational Psychology, 98(4), 891. https://doi.org/10.1037/0022-0663.98.4.891

Cho, Y. H., \& Cho, K. (2011). Peer reviewers learn from giving comments. Instructional Science, 39(5), 629-643. https://doi.org/10.1007/s11251-010-9146-1

Committee on the Foundations of Assessment. (2001). Knowing What Students Know: The Science and Design of Educational Assessment. https://doi.org/10.17226/10019

Crisp, G., Guàrdia, L., \& Hillier, M. (2016). Using e-Assessment to enhance student learning and evidence learning outcomes. International Journal of Educational Technology in Higher Education, 13(1), 18. https://doi.org/10.1186/s41239-016-0020-3

Darling-Hammond, L., \& Adamson, F. (2010). Beyond basic skills: The role of performance assessment in achieving 21st century standards of learning. In Stanford Center for Opportunity Policy in Education (SCOPE), Stanford University, School of Education. Retrieved from http://edpolicy. stanford. edu. Retrieved from https://edpolicy.stanford.edu/sites/default/files/beyond-basicskills-role-performance-assessment-achieving-21st-century-standards-learning-report_0.pdf Dawson, P., \& Henderson, M. (2017). How Does Technology Enable Scaling Up Assessment for Learning? In Scaling up Assessment for Learning in Higher Education (pp. 209-222). Springer. Retrieved from http://link.springer.com/chapter/10.1007/978-981-10-3045-1_14

Ferguson, R. (2012). The State of Learning Analytics in 2012: A Review and Future Challenges (Technical Report No. kmi-12-01). Knowledge Media Institute: The Open University, UK. Retrieved from http://kmi.open.ac.uk/publications/pdf/kmi-12-01.pdf

Ferguson, R., Clow, D., Macfadyen, L., Essa, A., Dawson, S., \& Alexander, S. (2014). Setting learning analytics in context: overcoming the barriers to large-scale adoption. In Proceedings of the 
Fourth International Conference on Learning Analytics And Knowledge (pp. 251-253). ACM.

Retrieved from http://dl.acm.org/citation.cfm?id=2567592

Fives, H., Barnes, N., Buehl, M. M., Mascadri, J., \& Ziegler, N. (2017). Teachers' Epistemic Cognition in Classroom Assessment. Educational Psychologist, 52(4), 270-283. https://doi.org/10.1080/00461520.2017.1323218

Gielen, M., \& De Wever, B. (2015). Structuring peer assessment: Comparing the impact of the degree of structure on peer feedback content. Computers in Human Behavior, 52, 315-325. Retrieved from http://www.sciencedirect.com/science/article/pii/S0747563215004598

Knight, S., Buckingham Shum, S., \& Littleton, K. (2014). Epistemology, assessment, pedagogy: where learning meets analytics in the middle space. Journal of Learning Analytics, 1(2), 23-47. http://dx.doi.org/10.18608/jla.2014.12.3

Knight, S., Buckingham Shum, S., Ryan, P., Sándor, Á., \& Wang, X. (2017). Academic Writing Analytics for Civil Law: Participatory Design Through Academic and Student Engagement. International Journal of Artificial Intelligence in Education. https://doi.org/10.1007/s40593-016-0120-1

Linn, R. L., Baker, E. L., \& Dunbar, S. B. (1991). Complex, Performance-Based Assessment: Expectations and Validation Criteria. Educational Researcher, 20(8), 15-21. https://doi.org/10.3102/0013189X020008015

Lockyer, L., Heathcote, E., \& Dawson, S. (2013). Informing Pedagogical Action: Aligning Learning Analytics With Learning Design. American Behavioral Scientist, 0002764213479367. https://doi.org/10.1177/0002764213479367

Lundstrom, K., \& Baker, W. (2009). To give is better than to receive: The benefits of peer review to the reviewer's own writing. Journal of Second Language Writing, 18(1), 30-43. Retrieved from http://www.sciencedirect.com/science/article/pii/S1060374308000313 
Mandinach, E. B. (2012). A perfect time for data use: Using data-driven decision making to inform practice. Educational Psychologist, 47(2), 71-85. Retrieved from http://www.tandfonline.com/doi/abs/10.1080/00461520.2012.667064

Mandinach, E. B., \& Gummer, E. S. (2016). What does it mean for teachers to be data literate: Laying out the skills, knowledge, and dispositions. Teaching and Teacher Education, 60, 366-376. https://doi.org/10.1016/j.tate.2016.07.011

McConlogue, T. (2015). Making judgements: investigating the process of composing and receiving peer feedback. Studies in Higher Education, 40(9), 1495-1506. Retrieved from http://www.tandfonline.com/doi/abs/10.1080/03075079.2013.868878

Mislevy, R., Behrens, J. T., Dicerbo, K. E., \& Levy, R. (2012). Design and discovery in educational assessment: evidence-centred design, psychometrics, and educational data mining. Journal of Educational Data Mining, 4(1), 11-48. Retrieved from http://researchnetwork.pearson.com/wpcontent/uploads/MislevyEtAIVol4Issue1P11_48.pdf

Muis, K. R., \& Franco, G. M. (2009). Epistemic beliefs: Setting the standards for self-regulated learning. Contemporary Educational Psychology, 34(4), 306-318. https://doi.org/10.1016/j.cedpsych.2009.06.005

Nelson, M. M., \& Schunn, C. D. (2009). The nature of feedback: how different types of peer feedback affect writing performance. Instructional Science, 37(4), 375-401. https://doi.org/10.1007/s11251-008-9053-x

Nguyen, H., Xiong, W., \& Litman, D. (2017). Iterative Design and Classroom Evaluation of Automated Formative Feedback for Improving Peer Feedback Localization. International Journal of Artificial Intelligence in Education, 1-41. https://doi.org/10.1007/s40593-016-0136-6 
Nicol, D., Thomson, A., \& Breslin, C. (2014). Rethinking feedback practices in higher education: a peer review perspective. Assessment \& Evaluation in Higher Education, 39(1), 102-122. Retrieved from http://www.tandfonline.com/doi/abs/10.1080/02602938.2013.795518

O'Donovan, B. (2017). How student beliefs about knowledge and knowing influence their satisfaction with assessment and feedback. Higher Education, 74(4), 617-633.

Pardo, A. (2017). A feedback model for data-rich learning experiences. Assessment \& Evaluation in Higher Education, 1-11. Retrieved from http://www.tandfonline.com/doi/abs/10.1080/02602938.2017.1356905

Patchan, M. M., Charney, D., \& Schunn, C. D. (2009). A validation study of students' end comments: Comparing comments by students, a writing instructor, and a content instructor. Journal of Writing Research, 124-152. Retrieved from http://dscholarship.pitt.edu/22893/1/JoWR_2009_vol1_nr2_Patchan_et_al.pdf

Pellegrino, J. W. (2013). Measuring What Matters in a Digital Age: Technology and the Design of Assessments for Multisource Comprehension. In D. G. Sampson, P. Isaias, D. Ifenthaler, \& J. M. Spector (Eds.), Ubiquitous and Mobile Learning in the Digital Age (pp. 259-286). New York, NY, USA: Springer. Retrieved from http://link.springer.com/chapter/10.1007/978-1-4614-3329-3_17

Price, M., Rust, C., O’Donovan, B., Handley, K., \& Bryant, R. (2012). Assessment literacy: The foundation for improving student learning. ASKe, Oxford Centre for Staff and Learning Development.

Roll, I., \& Wylie, R. (2016). Evolution and Revolution in Artificial Intelligence in Education. International Journal of Artificial Intelligence in Education, 26(2), 582-599. https://doi.org/10.1007/s40593016-0110-3

Rollinson, P. (2005). Using peer feedback in the ESL writing class. ELT Journal, 59(1), 23-30. Retrieved from http://eltj.oxfordjournals.org/content/59/1/23.short 
Rust, C., O’Donovan, B., \& Price, M. (2005). A social constructivist assessment process model: how the research literature shows us this could be best practice. Assessment \& Evaluation in Higher Education, 30(3), 231-240. https://doi.org/10/cjdtfd

Schwartz, D. L., \& Arena, D. (2013). Measuring what matters most: Choice-based assessments for the digital age. Boston Massachusetts: MIT Press.

Shermis, M. D., \& Burstein, J. (2013). Handbook of Automated Essay Evaluation: Current Applications and New Directions. Routledge.

Shibani, A. (2017). Combining Automated and Peer Feedback for Effective Learning Design in Writing Practices. In Y. Yu, S. Murthy, B. Chang, M. Chang, G. Biswas, \& J. Mason (Eds.), Proceedings of the 25th International Conference on Computers in Education. Canterbury, New Zealand: AsiaPacific Society for Computers in Education. Retrieved from http://icce2017.canterbury.ac.nz/proceedings

Shibani, A. (2018). Developing a Learning Analytics Intervention Design and tool for Writing Instruction. In S. Buckingham Shum, R. Ferguson, A. Merceron, \& X. Ochoa (Eds.), Companion Proceedings 8th International Conference on Learning Analytics \& Knowledge (LAK18)vvvv. Sydney, Australia: Society for Learning Analytics Research (SoLAR). Retrieved from http://bit.ly/lak18-companionproceedings

Shibani, A., Knight, S., Buckingham Shum, S., \& Ryan, P. (2017). Design and Implementation of a Pedagogic Intervention Using Writing Analytics. In W. Chen, J.-C. Yang, A. F. Mohd Ayub, S. L. Wong, \& A. Mitrovic (Eds.), 25th International Conference on Computers in Education (pp. 306315). Christchurch, New Zealand: Asia-Pacific Society for Computers in Education. Retrieved from http://icce2017.canterbury.ac.nz/sites/default/files/proceedings/main/C3/Design\%20and\%20I 
mplementation\%20of\%20a\%20Pedagogic\%20Intervention\%20Using\%20Writing\%20Analytics.pd $f$

Stecher, B. (2010). Performance assessment in an era of standards-based educational accountability. Standford Center for Opportunity Policy in Education. Retrieved from http://edpolicy.stanford.edu/sites/default/files/publications/performance-assessment-erastandards-based-educational-accountability_0.pdf

Strijbos, J.-W., \& Sluijsmans, D. (2010). Unravelling peer assessment: Methodological, functional, and conceptual developments. Learning and Instruction, 20(4), 265-269. https://doi.org/10.1016/j.learninstruc.2009.08.002

Timmis, S., Broadfoot, P., Sutherland, R., \& Oldfield, A. (2016). Rethinking assessment in a digital age: Opportunities, challenges and risks. British Educational Research Journal, 42(3), 454-476. Retrieved from http://onlinelibrary.wiley.com/doi/10.1002/berj.3215/full

Topping, K. (1998). Peer assessment between students in colleges and universities. Review of Educational Research, 68(3), 249-276. https://doi.org/10.3102/00346543068003249

Watson, W., \& Ishiyama, J. (2012). Using Calibrated Peer Review to Facilitate Writing Assignments in Large Political Science Classes. In APSA 2012 Teaching \& Learning Conference Paper. University of North Carolina (UNC) at Chapel Hill. Retrieved from http://papers.ssrn.com/sol3/papers.cfm?abstract_id=1997612

Whitelock, D. (2010). Activating assessment for learning: are we on the way with web 2.0? In Web (Vol. 2, pp. 319-342).

Whitelock, D., Gilbert, L., Hatzipanagos, S., Watt, S., Zhang, P., Gillary, P., \& Recio, A. (2012). Addressing the challenges of assessment and feedback in higher education: a collaborative effort across three UK universities. Retrieved from http://eprints.soton.ac.uk/273207/ 
Whitelock, D., Pinto, R., \& Saez, M. la. (2010). Modelling the teachers' feedback process for the design of an electronic interactive science tool with automatic feedback. International Journal of Continuing Engineering Education and Life Long Learning, 20(2), 189-207. Retrieved from http://www.inderscienceonline.com/doi/abs/10.1504/IJCEELL.2010.036815

Wimshurst, K., \& Manning, M. (2013). Feed-forward assessment, exemplars and peer marking: evidence of efficacy. Assessment \& Evaluation in Higher Education, 38(4), 451-465. Retrieved from http://www.tandfonline.com/doi/abs/10.1080/02602938.2011.646236

Yadav, R. K., \& Gehringer, E. F. (2016). Metrics for Automated Review Classification: What Review Data Show. In State-of-the-Art and Future Directions of Smart Learning (pp. 333-340). Springer. Retrieved from http://link.springer.com/chapter/10.1007/978-981-287-868-7_41

Zhao, Y., Pugh, K., Sheldon, S., \& Byers, J. L. (2002). Conditions for classroom technology innovations. Teachers College Record, 104(3), 482-515. Retrieved from http://crcsalon.pbworks.com/f/Conditions+for+Classroom+Technology+Innovations.pdf 